\title{
EDITORIAL
}

\section{LAS INVESTIGACIONES DE ENFERMERÍA RELACIONADAS CON LA SALUD DEL TRABAJADOR}

\author{
María LuCia do Carmo RobÁZzi ${ }^{*}$
}

T a Salud del Trabajador (ST) es un campo aún en construcción. Sus orígenes fueron los movimientos sociales en respuesta a las empresas y al Estado que se preocupaban muy escasamente de generar políticas efectivas en este ámbito; los actores provenían de sectores sindicales y también profesionales, que optaron por la centralidad de la categoría trabajo $(1,2)$. En la ST se consideran los impactos del trabajo sobre el cuerpo del individuo, sin embargo, también hay espacio para la subjetividad, los saberes y las percepciones de los trabajadores sobre sus actividades (3).

La enfermería es una ciencia en constante crecimiento, evolución y construcción. Hace algunos años se abordaron principalmente aspectos relacionados con el cuidar, sin embargo se ha ido volviendo la mirada hacia otros campos de actuación e investigación y, entre éstos, está la salud de los trabajadores. En países como Brasil, algunos programas de postgrado en enfermería ya presentan líneas de investigación en esta temática.

La investigación generada por enfermeras y enfermeros se direcciona a los trabajadores jóvenes y niños (4), adultos y personas mayores (5), relacionados con accidentes y enfermedades causadas por el trabajo (6), los riesgos profesionales, incluyendo la vivencia de violencia (7), estrés y síndrome de burnout (8), exceso de trabajo (9), entre otras temáticas importantes de investigación. Este hecho demuestra el robusto desarrollo de la ciencia de enfermería, abarcando el ámbito de la salud de los trabajadores. Sin embargo, se hacen necesarios más estudios, a fin de elucidar los efectos perjudiciales del trabajo sobre la salud de las personas que trabajan, incluidos los trabajadores de la propia enfermería.

*Profesora Titular de la Escuela de Enfermería de Ribeirão Preto, Brasil. 


\section{REFERÊNCIAS}

1. Gomes-Minayo C, Thedim-Costa S. A construção do campo da saúde do trabalhador: percurso e dilemas. Cad Saúde Pública. 1997; v. 13, supl. 2, p. 21-32.

2. Louzada RCR. A Pesquisa em Saúde do Trabalhador no Brasil: Anotações Preliminares. Rev. Espaço Aberto, s/d.

3. Lacaz FAC. Saúde do trabalhador: um estudo sobre as formações discursivas da academia, dos serviços e do movimento sindical. Tese de doutorado. Departamento de Medicina Preventiva e Social, Faculdade de Ciências Médicas, Unicamp, 1996, Campinas, 435 pp.

4. Da Penha Silveira RC, Do Carmo Cruz Robazzi ML. Acidentes de trabalho entre crianças e adolescentes atendidos pelo setor público de saúde, Ribeirão Preto, São Paulo, Brasil. Cienc. enferm. 2003; v. 9, № 2, p. 43-55.

5. Robazzi MLCC, Marziale MHP, Rodrigues RAP, SILVEIRA CA, Alves LA. Acidentes e agravos à saúde dos idosos nos ambientes de trabalho. Revista Enfermagem (UERJ), 2009, v. 17, p 309-314.

6. Sêcco IAO, Robazzi MLCC, Shimizu DS, Rúbio MMS. Typical occupational accidents with employees of a university hospital in the South of Brazil: epidemiology and prevention. Rev Latino-am Enfermagem. 2008; v. 16, № 5, p. 824-31.

7. Paravic Klijn T, Valenzuela Suazo S, Burgos Moreno M. Violencia percibida por trabajadores de atención primaria de salud. Cienc. enferm. 2004; v. 10, № 2, p. 53-65.

8. Moreira DS, Magnago RF, Sakae TM, Magajewski FRL. Prevalência da síndrome de burnout em trabalhadores de enfermagem de um hospital de grande porte da Região Sul do Brasil. Cad. Saúde Pública. 2009; v. 25, № 7, p. 1559-68.

9. Robazzi MLCC, Mauro MYC, Dalri RCMB, Silva LA, Sêcco IAO, Pedrão LJ. Exceso de trabajo y agravios mentales a los trabajadores de la salud. Revista Cubana de Enfermería (Impresa). 2010; v. 26, p. 52-64. 